\title{
Course of health care costs before and after psychiatric inpatient treatment: patient-reported vs. administrative records
}

\section{Nadja Zentner, Ildiko Baumgartner, Thomas Becker, Bernd Puschner}

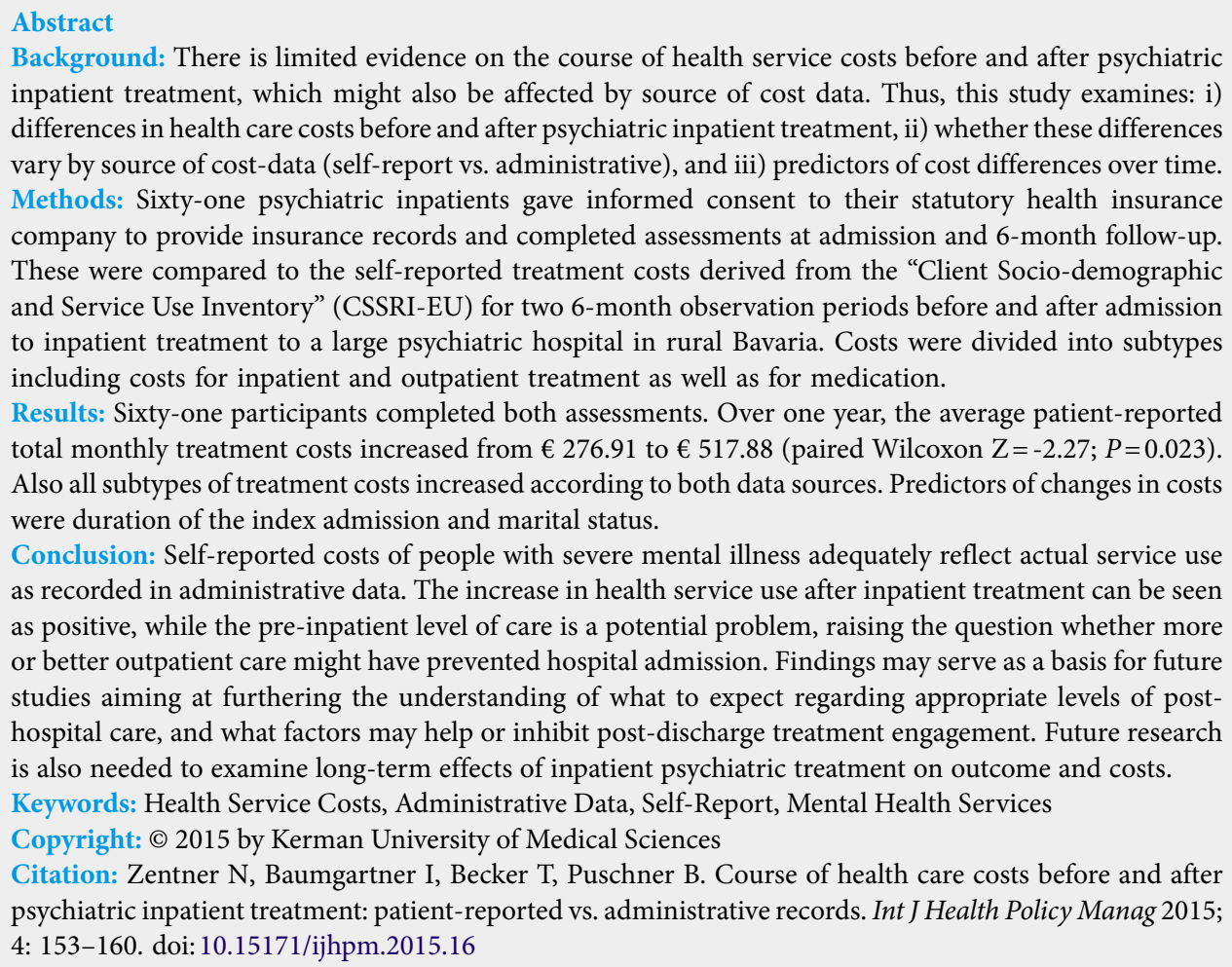
inpatient treatment, which might also be affected by source of cost data. Thus, this study examines: i) differences in health care costs before and after psychiatric inpatient treatment, ii) whether these differences vary by source of cost-data (self-report vs. administrative), and iii) predictors of cost differences over time. Methods: Sixty-one psychiatric inpatients gave informed consent to their statutory health insurance company to provide insurance records and completed assessments at admission and 6-month follow-up. These were compared to the self-reported treatment costs derived from the "Client Socio-demographic and Service Use Inventory" (CSSRI-EU) for two 6-month observation periods before and after admission to inpatient treatment to a large psychiatric hospital in rural Bavaria. Costs were divided into subtypes including costs for inpatient and outpatient treatment as well as for medication.

Results: Sixty-one participants completed both assessments. Over one year, the average patient-reported total monthly treatment costs increased from $€ 276.91$ to $€ 517.88$ (paired Wilcoxon $Z=-2.27 ; P=0.023$ ). Also all subtypes of treatment costs increased according to both data sources. Predictors of changes in costs were duration of the index admission and marital status.

Conclusion: Self-reported costs of people with severe mental illness adequately reflect actual service use as recorded in administrative data. The increase in health service use after inpatient treatment can be seen as positive, while the pre-inpatient level of care is a potential problem, raising the question whether more or better outpatient care might have prevented hospital admission. Findings may serve as a basis for future studies aiming at furthering the understanding of what to expect regarding appropriate levels of posthospital care, and what factors may help or inhibit post-discharge treatment engagement. Future research is also needed to examine long-term effects of inpatient psychiatric treatment on outcome and costs. Keywords: Health Service Costs, Administrative Data, Self-Report, Mental Health Services

Copyright: (C) 2015 by Kerman University of Medical Sciences

Citation: Zentner N, Baumgartner I, Becker T, Puschner B. Course of health care costs before and after psychiatric inpatient treatment: patient-reported vs. administrative records. Int J Health Policy Manag 2015; 4: 153-160. doi: 10.15171/ijhpm.2015.16

\section{Article History:}

Received: 18 August 2014 Accepted: 22 January 2015 ePublished: 27 January 2015

\section{Key Messages}

Implications for policy makers

- Inpatient treatment seems to motivate people with severe mental illness to seek more community treatment. A better coordination of community services after discharge might improve quality and efficiency of care and further increase community tenure.

- Self-reported costs of people with severe mental illness adequately reflect actual service use as recorded in administrative data. This means that people with severe mental illness are able to provide accurate information about service utilization. However, the conversion of self-reported utilization data to costs is laborious and its quality depends on the accuracy of unit costs.

- The finding that length of inpatient stay predicted increase of certain subtypes of costs (outpatient services and medication) indicates that a better coordination of services for long-stay patients is necessary.

\section{Implications for public}

Health economic analyses are required to make informed and fair health care decisions. Their accuracy hinges upon the quality of cost data. However, the collection of cost data is laborious and sometimes not even possible because researchers do not have access to the funders' records. This study examined whether inpatient mental health care, which is an expensive form of treatment, brings about a cost-offset. It was found that people with severe mental illness did not reduce utilization of health services after discharge. Rather, intensive long-term community care is required to avoid costly readmissions to hospital. Another main finding of this study was that self-reported cost data by and large correspond to data from administrative records provided by a health insurance company. This implies that self-report data provided by people with mental illness are a good basis for health economic analysis. 


\section{Background}

Concern over growing healthcare costs has increased the pressure to develop cost-containment mechanisms such as disease management programs or integrated care $(1,2)$. These are systemic approaches of managed care to reduce health care costs while keeping stable or even improving the quality of care. Integrated care, continuing care, and implementation of measurement-based care are successful approaches to improve patient outcome (3-6) with the potential to increase interest of mental health care providers in routine data collection and patient symptoms reporting (7).

Furthermore, costs might be saved and outcomes improved by substituting expensive inpatient services by appropriate outpatient and community services $(1,8-10)$. A study in a primary care setting found that patient-centered care contributes to decreasing the use of health care resources and associated costs (11). It has also been shown that the integration of substance abuse treatment or mental health care into primary care contributes to a decrease of inpatient days and total medical costs $(12,13)$. Furthermore, it has been found that a greater stability of care between patients with severe mental illness results in lower hospital costs and greater community costs (14).

In Germany, beginning with the mental health care reform in the 1970's, there have been steps towards closing the gap between inpatient and outpatient mental health care by introducing community mental health services such as psychiatric day hospitals, implementing social psychiatric services and hospital-based outpatient services, and also by developing case management, managed care and other services to coordinate these services (15). Despite positive developments in community care, compared to other Western countries, inpatient treatment is still a mainstay of psychiatric treatment. Although the reduction of the number of psychiatric beds has led to a decrease of the mean duration of inpatient stays in hospitals for psychiatry and psychotherapy from 64.8 days in 1991 to 22.9 days in 2010, during the same period, numbers of people having received inpatient care nearly doubled from 406,910 (1991) to 805,287 (2010) (16), and the rehospitalization rate rose from 0.55 (1999) to 0.65 (2002) (17). At the same time, health care costs for mental and behavioral disorders substantially increased in Germany during the last years (by $23 \%$ from 2002 to 2008 to $€ 28.6$ billion) (18).

This raises the question whether inpatient psychiatric treatment affects service utilization costs after discharge in the sense of the so-called cost-offset effect. Cost-offset suggests that the cost of inpatient treatment may be offset by a reduction in future general medical use and health care costs $(19,20)$. Findings on cost-offset in mental health care are heterogeneous. A meta-analysis found that the strongest effect was in the reduction of inpatient rather than outpatient costs (21). Also older patients showed greater cost-offset effects $(21,22)$. Von Korff and colleagues (23) found a costoffset in specialty mental health care for patients with major depression, but not for general medical services. Patients with diabetes and depression who received a stepped collaborative care intervention had greater mental health service costs, but non-mental health medication costs and other outpatient costs were lower. Another study found that treated anxious or depressed primary care patients with higher functional status had greater cost savings one year after the beginning mental health treatment (24). Also some other studies have reported a cost reduction after inpatient psychiatric treatment $(25,26)$. However, it has also been argued that cost-offsets are unlikely in the treatment of people with severe mental illness, and that these patients may become more costly when they have more and adequate access to medical services $(19,27)$.

In sum, little is known about course of health care costs before and after inpatient mental health care, and whether cost changes over time are affected by source of cost data and patient characteristics. Thus, building on a previous paper which analyzed baseline data only (28), the present exploratory study will: i) examine differences in total and subtypes of health care costs (inpatient, outpatient, medication) before and after psychiatric inpatient treatment, ii) scrutinize whether these differences vary by source of cost data (self-report vs. administrative records), and iii) analyze predictors of cost differences over time.

\section{Methods}

Between September 2005 and March 2007, 507 adults with mental illness admitted to inpatient treatment at a large psychiatric hospital in rural Bavaria (Ulm University's Clinic for Psychiatry and Psychotherapy II at Günzburg District Hospital) were asked to participate in the study "Outcome monitoring and outcome management in inpatient psychiatric care" (EMM, ISRCTN93197945) (29). Inclusion criteria were admission to inpatient psychiatric treatment, and age of 18-65 years. Exclusion criteria were a main diagnosis of organic mental disorder or substance abuse, and insufficient command of the German language. Patients received $€ 20$ for participation in the study, and clinicians got a book voucher worth $€ 50$. Of the 507 screened patients, $141(27.81 \%)$ refused to participate, and 72 (14.20\%) did not meet the inclusion criteria. 294 (57.99\%) patients gave written informed consent to participate in the study. Ninety-three (31.63\%) of these were insured with a major statutory health insurance company (AOK Swabia), of which $82(88.17 \%)$ additionally gave informed consent to the AOK Swabia to forward their insurance records to the EMM research team. The focus on insurees of the AOK Swabia was chosen for pragmatic reason because this is the insurance company covering the treatment costs of the largest number of patients receiving inpatient treatment at Ulm University's Clinic for Psychiatry and Psychotherapy II, while other participants' treatment costs were reimbursed by a large number $(\mathrm{N}=20)$ other statutory or private health insurance companies. Figure 1 gives an overview of flow of participants through the stages of the study.

Participants were interviewed by trained research workers at the hospital at admission (T0). For the assessment at sixmonth follow-up (T1), the participant was either interviewed at home, or came to the hospital.

\section{Measures}

Socio-demographic data and service use

Patient socio-economic status and health service use were assessed via the German Version (30) of the "Client Sociodemographic and Service Receipt Inventory - European 


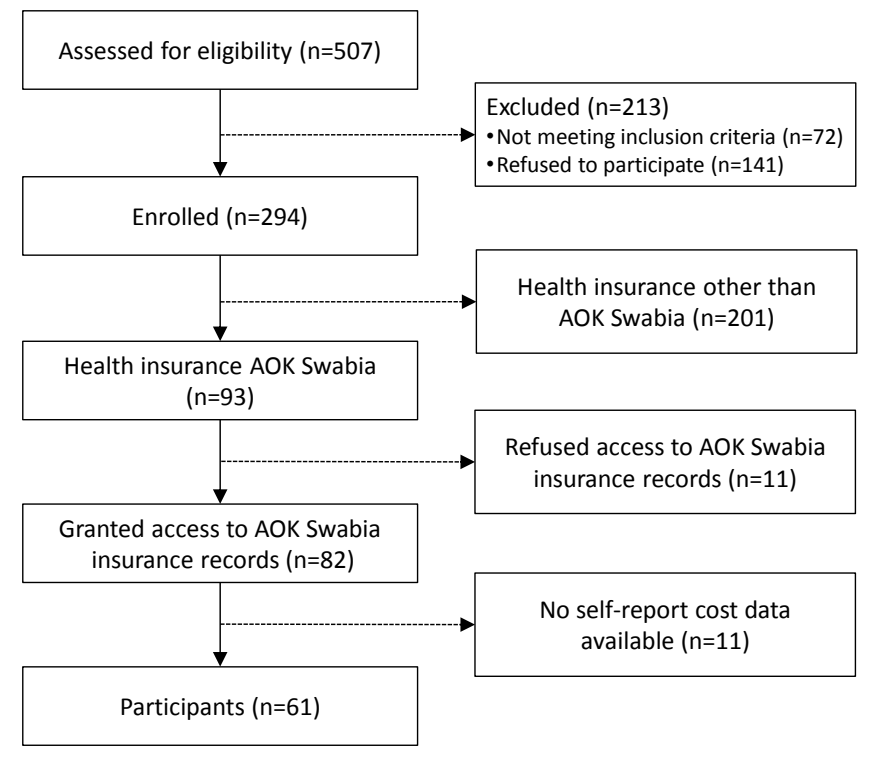

Figure 1. Participant flow

Version" (CSSRI-EU) (31) which is structured into five sections: i) Socio-demographic data; ii) Living situation; iii) Employment and income; iv) Service receipt: inpatient, day clinic, and outpatient service use; and v) Medication: name of drug, dosage form, prescribed daily dose, and frequency. The periods covered by the CSSRI were six months for inpatient service use, three months for outpatient service use, and one month for consumption of medication. Participants were asked at admission (T0) and at 6-month follow-up (T1) to complete the CSSRI-EU (see Figure 2).

\section{Diagnosis and outcome}

Diagnosis according to ICD-10 chapter V (32) was recorded by practitioners with advanced training in psychiatry or clinical psychology and entered into the hospitals documentation system. No structured clinical interview was used to confirm diagnoses. Diagnoses were grouped into schizophrenia (F2), affective disorders (F3), and other mental disorders (F4, F5, F6, and F7). Patient mental health was measured with the German version $(33,34)$ of the Outcome Questionnaire 45 (OQ-45.2) (35), which is a self-report measure widely used for outcome assessment in mental health services. The OQ45.2 contains 45 items (five-point Likert scale: never $=0$, rarely $=1$, sometimes $=2$, often $=3$, almost always $=4$ ). The Total Score (TOT) is the prorated (less than $20 \%$ missing items) sum score of all items, with a higher score indicating more impairment.

\section{Health service costs}

First, self-reported health service costs were calculated by allocating unit costs to the service use data provided by the participants in the CSSRI (see above) for different types of costs (inpatient, outpatient, medication). Inpatient: Psychiatric inpatient service use was calculated by multiplying the number of inpatient days (excluding the day of discharge) by the hospital's daily rate $(€ 226.58)$. For day-clinic care, the hospital's rate of $€ 140.73$ was used for all treatment days. The daily rate for rehabilitation facilities for people with mental illness was $€ 105.30$, and for somatic hospitals it was $€ 413.80$

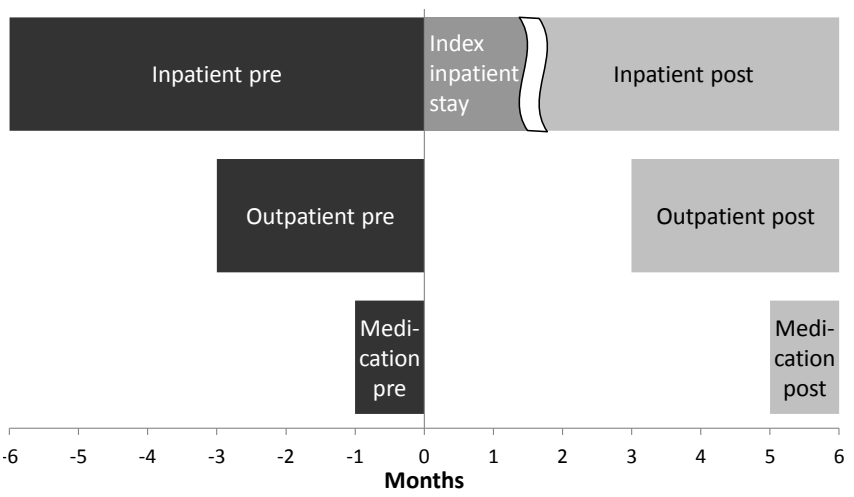

Figure 2. Assessment of self-reported health service use

(36). Outpatient: Cost of treatment in psychiatric outpatient clinics were determined using the estimated average case value of $€ 210.00$ per quarter (37). Costs for treatment by office-based psychiatrists and psychotherapists were defined using the contact values as fixed by their professional societies (€ 16.00 for psychiatrists and $€ 78.00$ for psychotherapists) (38) multiplied by the number of contacts as reported by the patients. The same procedure was used for calculating the costs of treatment by physicians of other professional groups on the basis of the Unified Rating scale (EBM) of the National Association of Statutory Health Insurance Physicians (NASHIP) $(39,40)$. Medication: On the basis of the patientreported use of medication during the observation period, costs of drugs were calculated using the "Red List" which is a widespread register for pharmaceutical drugs in Germany (41). The price per unit was derived from the price level for the largest package size (38). Then the unit price was multiplied by the prescribed daily dose and the number of prescription days. Furthermore, medications were divided into groups in order to derive costs for psychotropic drugs in addition to total costs for medications.

Second, administrative records of health service costs were taken from the health insurance records which were reported for each quarter of a year. For each study participant, the AOK Swabia provided the costs for inpatient and day-clinic service use via Excel spreadsheets. Costs of outpatient services were obtained from the Physicians' Association of Bavaria (KVB) through the AOK Swabia. Information on outpatient medication was also sent via Excel spreadsheets added by the complete records of prescribed recipes.

\section{Analysis}

Analyses were carried out by using IBM SPSS Statistics, version 20. All costs were expressed in Euros. Given different time intervals for self-reported health services in the CSSRI, and different reporting periods in both cost data sources, the costs were converted into monthly costs. Missing values in the self-reported medication data, e.g. due to lack of daily dose information, were imputed by the respective mean value. Only the outpatient medication costs were included in the analysis since medication consumed during inpatient treatment are included in the inpatient daily costs. Total treatment costs per source were calculated by adding inpatient (including day-clinic) and outpatient costs, and costs for outpatient medication. 
In addition to mean and standard deviation, quartiles and range were used to report properties of cost data which were distinctly right skewed with values of zero occurring frequently. Differences between the observation periods $\mathrm{T} 0$ and $\mathrm{T} 1$, and differences between the two sources were determined by using the non-parametric paired Wilcoxon rank sum test. Furthermore, as recommended by Kilian and colleagues (42), multiple linear regression analyses with a bootstrap technique (2,000 replications) were conducted to ascertain the effects of independent variables (SES, and illness characteristics) on the differences between the observation periods $\mathrm{T} 0$ and $\mathrm{T} 1$ of both data sources for each group of costs as well as for total costs.

\section{Results}

Sample

Sixty-one participants completed both assessments and were no longer hospitalized at T1. As shown in Table 1, at study intake, participants were in their early forties, on average. Slightly more than half of them were female, and about one- third lived alone. The majority had a low educational degree and over $60 \%$ were not in paid employment. As also shown, at study intake, the majority of participants received the primary diagnosis of an affective disorder. The mean length of index stay was six and a half weeks. A drop-out analysis showed that, compared to the participants with self-report only, this sample had a lower educational degree, and a shorter length of index stay.

Changes in health service costs over time by data source Excluding the index admission, average total monthly treatment costs significantly increased over time in patient report as well as in administrative records (see Table 2 and Table 3).

For subtypes of costs, a significant increase was found for medication and use of psychotropic drugs in both self-report and administrative records, but not for inpatient or outpatient service use. As shown in Table 4 and illustrated in Figure 3, the differences in total treatment costs between $\mathrm{T} 0$ and $\mathrm{T} 1$ were independent of the data source which was also the case

Table 1. Participants' socio-demographic and clinical characteristics at admission

\begin{tabular}{|c|c|c|c|}
\hline & $\begin{array}{l}\text { Administrative data and self-report } \\
(\mathrm{N}=61)\end{array}$ & $\begin{array}{l}\text { Self-report only } \\
(N=233)\end{array}$ & Difference \\
\hline Age, years; M (SD) & $42.71(12.20)$ & $40.83(11.90)$ & $\mathrm{F}_{(\mathrm{df}=292)}=1.19 ; P=0.276$ \\
\hline Length of index stay, days; M (SD) & $46.75(33.66)$ & $63.91(61.82)$ & $\mathrm{F}_{(\mathrm{df}=292)}=4.35 ; P=0.044$ \\
\hline OQ-45.2 TOT; M (SD) & $77.18(23.87)$ & $79.52(28.93)$ & $F_{(d f=292)}=0.34 ; P=0.562$ \\
\hline Diagnosis: F2ª $\mathrm{N}(\%)$ & $18(29.51)$ & $67(28.76)$ & $\chi_{(\mathrm{df}=2)}^{2}=0.17 ; P=0.918$ \\
\hline $\mathrm{F}^{\mathrm{b}} ; \mathrm{N}(\%)$ & $33(54.10)$ & $132(56.65)$ & \\
\hline $\mathrm{F} 4, \mathrm{~F} 5, \mathrm{~F} 6, \mathrm{~F} 7^{\mathrm{c}} ; \mathrm{N}(\%)$ & $10(16.39)$ & $34(14.59)$ & \\
\hline Gender, female; N (\%) & 35 (57.38) & $104(44.64)$ & $\chi_{(\mathrm{df}=1)}^{2}=3.15 ; P=0.085$ \\
\hline Marital status: single; N (\%) & $23(37.70)$ & $102(43.78)$ & $\chi_{(\mathrm{df}=2)}^{2}=0.89 ; P=0.642$ \\
\hline Married; N (\%) & $21(34.43)$ & $77(33.05)$ & \\
\hline Other ${ }^{\mathrm{d}} ; \mathrm{N}(\%)$ & $17(27.87)$ & $54(23.18)$ & \\
\hline Educational level: high track ${ }^{\mathrm{e}}$; N (\%) & $4(6.56)$ & 34 (14.91) & $\chi_{(\mathrm{df}=2)}^{2}=15.76 ; P=0.001$ \\
\hline Low track'; N (\%) & $50(81.97)$ & $123(53.95)$ & \\
\hline Work: full-/part-time; N (\%) & $22(36.07)$ & $102(44.93)$ & $\chi_{(\mathrm{df}=1)}^{2}=1.54 ; P=0.214$ \\
\hline Not working; N (\%) & 39 (63.93) & $125(55.07)$ & \\
\hline
\end{tabular}

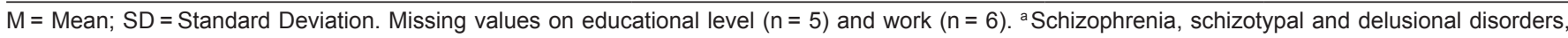
${ }^{b}$ Affective disorders, ${ }^{c} \mathrm{~F} 4=$ Neurotic, stress-related and somatoform disorders, F5 = Behavioral syndromes associated with physiological disturbances and physical factors, F6 = Disorders of adult personality and behavior, F7 = Mental retardation, 'separated, divorced or widowed, "Abitur", "Realschule", "Hauptschule" or lower.

Table 2. Monthly costs in $€$ of patient-reported health service use $(\mathrm{N}=61)$

\begin{tabular}{|c|c|c|c|c|c|c|c|c|}
\hline & & $M$ & SD & Range & 25\% Quantile & Median & 75\% Quantile & Difference $^{a}$ \\
\hline \multirow{2}{*}{ Inpatient } & TO & 134.18 & 426.05 & 2265.80 & 0.00 & 0.00 & 0.00 & \multirow{2}{*}{$Z=-0.78 ; P=0.435$} \\
\hline & $\mathrm{T} 1$ & 272.23 & 792.55 & 3858.12 & 0.00 & 0.00 & 0.00 & \\
\hline \multirow{2}{*}{ Outpatient } & TO & 93.68 & 117.84 & 720.72 & 16.00 & 57.39 & 131.32 & \multirow{2}{*}{$Z=-1.22 ; P=0.221$} \\
\hline & $\mathrm{T} 1$ & 120.37 & 166.86 & 1051.43 & 19.72 & 68.80 & 139.87 & \\
\hline \multirow{2}{*}{ Medication } & TO & 49.05 & 79.25 & 318.48 & 0.00 & 0.00 & 82.26 & \multirow{2}{*}{$Z=-3.96 ; P<0.001$} \\
\hline & $\mathrm{T} 1$ & 125.29 & 198.89 & 1077.80 & 9.41 & 69.82 & 159.01 & \\
\hline \multirow{2}{*}{ Psychotropic drugs } & TO & 43.92 & 73.80 & 318.48 & 0.00 & 0.00 & 54.83 & \multirow{2}{*}{$Z=-4.30 ; P<0.001$} \\
\hline & $\mathrm{T} 1$ & 115.91 & 172.89 & 1048.77 & 24.47 & 72.64 & 125.72 & \\
\hline \multirow{2}{*}{ Total $^{\mathrm{b}}$} & TO & 276.91 & 442.23 & 2417.04 & 51.34 & 112.18 & 296.30 & \multirow{2}{*}{$Z=-2.27 ; P=0.023$} \\
\hline & $\mathrm{T} 1$ & 517.88 & 812.82 & 3899.12 & 101.23 & 214.87 & 431.19 & \\
\hline
\end{tabular}

$\mathrm{M}=$ Mean; SD = Standard Deviation; ${ }^{a}$ paired Wilcoxon rank sum test; ${ }^{\mathrm{b}}$ without costs for psychotropic drugs which are included in costs for medication. 
Table 3. Monthly costs in $€$ as documented in health insurance records $(\mathrm{N}=61)$

\begin{tabular}{|c|c|c|c|c|c|c|c|c|}
\hline & & M & SD & Range & 25\% Quantile & Median & 75\% Quantile & Difference $^{a}$ \\
\hline \multirow{2}{*}{ Inpatient } & TO & 413.42 & 862.62 & 4427.96 & 0.00 & 0.00 & 333.87 & \multirow{2}{*}{$Z=-1.66 ; P=0.097$} \\
\hline & $\mathrm{T} 1$ & 849.78 & 1489.53 & 7020.65 & 0.00 & 0.00 & 1361.80 & \\
\hline \multirow{2}{*}{ Outpatient } & TO & 93.20 & 85.72 & 499.34 & 45.23 & 65.53 & 120.79 & \multirow{2}{*}{$Z=-0.52 ; P=0.603$} \\
\hline & $\mathrm{T} 1$ & 102.71 & 88.18 & 424.62 & 46.81 & 76.26 & 117.02 & \\
\hline \multirow{2}{*}{ Medication } & TO & 88.55 & 102.23 & 402.87 & 13.39 & 42.45 & 124.10 & \multirow{2}{*}{$\mathrm{Z}=-3.77 ; P<0.001$} \\
\hline & $\mathrm{T} 1$ & 174.25 & 186.33 & 961.43 & 43.33 & 110.11 & 248.09 & \\
\hline Psychotropic drugs & $\mathrm{T} 1$ & 141.24 & 175.04 & 833.83 & 27.09 & 70.68 & 212.23 & $Z=-3.66 ; P<0.001$ \\
\hline \multirow{2}{*}{ Total $^{b}$} & TO & 595.16 & 927.49 & 4780.22 & 87.96 & 242.66 & 636.79 & \multirow{2}{*}{$Z=-3.24 ; P=0.001$} \\
\hline & $\mathrm{T} 1$ & 1126.75 & 1480.38 & 7018.30 & 248.28 & 426.20 & 1687.41 & \\
\hline
\end{tabular}

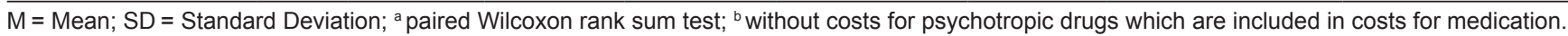

Table 4. Differences in health service costs in $€$ from T0 to T1 between self report and administrative records $(\mathrm{N}=61)$

\begin{tabular}{|c|c|c|c|c|c|c|c|c|}
\hline & & M & SD & Range & 25\% Quantile & Median & 75\% Quantile & Difference $^{a}$ \\
\hline \multirow{2}{*}{ Inpatient } & SR & 138.05 & 928.76 & 6123.92 & 0.00 & 0.00 & 0.00 & \multirow{2}{*}{$Z=-0.91 ; P=0.365$} \\
\hline & $A R$ & 436.36 & 1587.33 & 10304.01 & -94.07 & 0.00 & 509.11 & \\
\hline \multirow{2}{*}{ Outpatient } & SR & 26.69 & 194.40 & 1717.94 & -53.06 & 13.01 & 64.31 & \multirow{2}{*}{$Z=-0.17 ; P=0.866$} \\
\hline & $A R$ & 9.52 & 95.75 & 647.07 & -35.57 & -2.06 & 42.07 & \\
\hline \multirow{2}{*}{ Medication } & SR & 76.23 & 180.01 & 1200.20 & 0.00 & 44.65 & 96.67 & \multirow{2}{*}{$Z=-0.26 ; P=0.799$} \\
\hline & $A R$ & 85.71 & 183.02 & 1066.41 & -9.06 & 44.18 & 111.13 & \\
\hline Psychotropic drugs & $A R$ & 77.72 & 176.87 & 979.99 & -2.38 & 17.82 & 106.89 & $Z=-0.58 ; P=0.563$ \\
\hline \multirow{2}{*}{ Total $^{b}$} & SR & 240.97 & 957.68 & 6184.60 & -90.64 & 86.86 & 251.55 & \multirow{2}{*}{$\mathrm{Z}=-1.20 ; P=0.229$} \\
\hline & $A R$ & 531.58 & 1550.34 & 10164.42 & -27.27 & 147.96 & 522.83 & \\
\hline
\end{tabular}

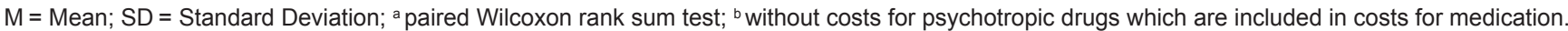

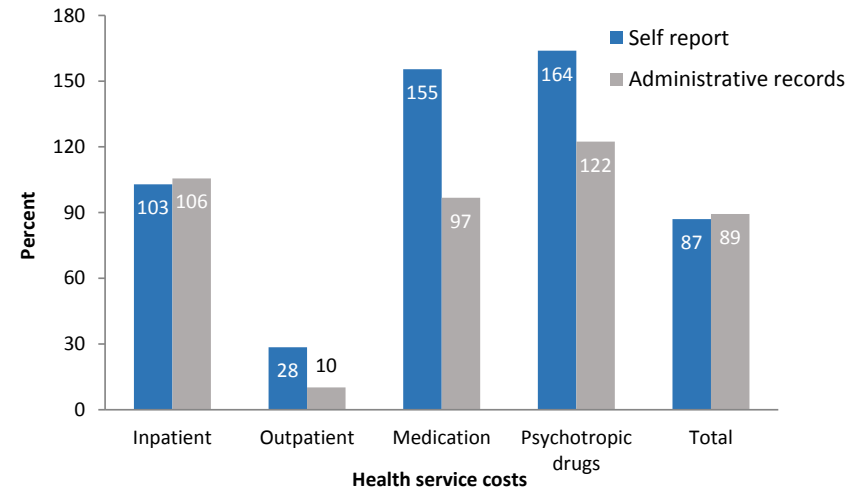

Figure 3. Changes of monthly health service costs from T0 to T1 $(\mathrm{N}=61)$

for each subtype of costs over time.

Prediction of changes over time in health service costs

Multiple linear regressions showed that none of the independent variables included in the models (gender, age, marital status, educational status, working status, length of index stay, as well as diagnosis and illness severity) predicted changes over time in self-reported total treatment costs and subtypes of costs for service use (inpatient services, medication, and psychotropic drugs). Table 5 shows that for outpatient costs, length of index stay was a significant predictor for changes in costs over time, i.e. with each extra day of index stay, the difference increased by $€ 2.35$ per month. The model explained $21.15 \%$ of the variance in cost changes. Five additional regressions tested the effect of the same predictors on changes over time for total treatment costs and subtypes of costs (inpatient and outpatient services, medication and psychotropic drugs) of the administrative records yielding $\mathrm{R}^{2}$ values of $0.21,0.24,0.27,0.41$, and 0.40 . Again, length of index stay $(\mathrm{B}=2.55$ and $\mathrm{B}=2.72)$ significantly predicted change of costs over time for psychotropic drugs and medication. Furthermore, changes over time for outpatient service costs were significantly predicted by marital status, with monthly costs increasing by $€ 67.61$ for participants who were married.

\section{Discussion}

The present study examined changes in health service costs during two 6-month observation periods before and after inpatient psychiatric treatment. Furthermore, differences between self-reported costs (SR) and administrative records (AR) were scrutinized.

\section{Change of costs over time}

This study found significant cost increases in total costs and costs for medication pre- and post-discharge. Also other subgroups of costs (inpatient and outpatient) increased, but changes did not reach statistical significance due to low sample size. This finding is in line with studies cited in a review of Olfson and colleagues showing that improved access to adequate services may increase treatment costs of people with severe mental illness (19).

Reasons for this are numerous, including heightened awareness of appropriate treatment options in the community through recommendations of key workers or other patients during inpatient treatment. After discharge, also caregivers might be motivated to take a closer look at the patient's needs for care and support the uptake of targeted assistance. 
Table 5. Predictors of change over time in self-reported monthly outpatient service costs in $€$ (multiple linear regression)

\begin{tabular}{|c|c|c|c|c|c|}
\hline & & B & SE & $P$ & $95 \% \mathrm{Cl}$ \\
\hline Constant & & 100.79 & 160.14 & 0.513 & $-219.239-437.855$ \\
\hline Gender $^{\mathrm{a}}$ & Female & -20.67 & 51.53 & 0.666 & $-146.474-57.296$ \\
\hline Age & Years & 1.52 & 2.18 & 0.475 & $-1.983-6.810$ \\
\hline \multirow{2}{*}{ Marital status ${ }^{\mathrm{b}}$} & Married & 0.79 & 82.29 & 0.991 & $-159.064-159.086$ \\
\hline & Other & -37.32 & 60.56 & 0.522 & $-147.902-97.530$ \\
\hline \multirow{2}{*}{ Educational level $^{\mathrm{c}}$} & Middle track & -65.76 & 136.38 & 0.564 & $-405.598-160.688$ \\
\hline & Low track & -40.04 & 123.71 & 0.671 & $-334.740-216.492$ \\
\hline Work $^{\mathrm{d}}$ & Not working & -28.03 & 53.49 & 0.609 & $-139.488-71.784$ \\
\hline \multirow{2}{*}{ Diagnosis; ICD-10 } & $\mathrm{F} 2$ & -8.38 & 61.30 & 0.895 & $-122.567-120.913$ \\
\hline & Other & 78.83 & 119.17 & 0.546 & $-117.676-336.135$ \\
\hline Illness severity; OQ-45.2 & TOT & -2.32 & 1.49 & 0.152 & $-5.529-0.117$ \\
\hline Length of index stay & Days & 2.35 & 0.82 & 0.024 & $1.011-4.287$ \\
\hline
\end{tabular}

Reference categories: ${ }^{\mathrm{a}}$ male; ${ }^{\mathrm{b}}$ single; ${ }^{\mathrm{c}}$ high track; ${ }^{\mathrm{d}}$ full-/part-time; ${ }^{\mathrm{e}} \mathrm{F} 3 . R^{2}=0.211 ; F=1.195(P=0.316)$.

Similarly, a study which evaluated health care services of former long-stay patients in Austria found that outpatient care entails significant cost savings, but in certain patients costs for outpatient care considerably exceeded expected hospitalization costs (43). Patients with more support needs caused higher costs, e.g. for accommodation in assisted living, full-time care, labor, and occupational therapies in sheltered workshops.

There is also evidence that prescription of newer and more expensive psychotropic medication in the hospital which is continuously consumed after discharge may lead to higher treatment costs $(44,45)$. Furthermore, as a review showed, patients who took this newer psychotropic medication have a greater prevalence of medical co-morbidity concerning type 2 diabetes, higher lipid levels, and obesity which may increase the risk of cardiovascular diseases and hypertension (46), which in turn might contribute to higher treatment costs. However, this finding is only tentative, as it might take a longer period of time than the one-year follow-up interval in this study for people consuming newer antipsychotic drugs to develop such conditions.

\section{Predictors of cost changes}

Regression analysis showed that the duration of the index psychiatric inpatients stay significantly predicted the pre-post difference of monthly self-reported outpatient service costs. The length of index stay was also a predictor for change over time of costs for psychotropic drugs and medication costs taken from the administrative records. This finding could, as above, indicate that a longer hospital stay stipulates more illness insight and acceptance of thorough treatment in the community. Furthermore, participants who are married had significant cost increases for monthly outpatient service costs of the administrative records. It can be assumed that marriage may be an indicator of positive social support that supports treatment engagement.

\section{Self-report vs. administrative data}

In line with studies elsewhere $(11,14,46-49)$ it was found that inpatient treatment costs accounted for most of the overall expenditures, while the proportions differed by data source before ( $\mathrm{SR}=48.46 \%$ vs. $\mathrm{AR}=69.46 \%)$, and after admission $(\mathrm{SR}=52.57 \%$ vs. $\mathrm{AR}=75.42 \%)$. Outpatient health service costs contributed the second largest share at T0 ( $\mathrm{SR}=33.83 \%$ vs. $A R=15.66 \%$ ) while at $\mathrm{T} 1$, according to self-report, costs for medication and outpatient service were about equal (24.19\% and $23.24 \%$ respectively). In administrative records, medication costs made up $15.46 \%$ of total costs, and outpatient health service costs only $9.12 \%$.

Another important result is that no cost differences over time between the two data sources were found. In line with our previous work (28), this suggests that self-report data adequately measure the "real" costs of health service use over time as evident in the health insurance records of people with severe mental illness and supports their use in health economic analyses.

\section{Limitations}

This study has a number of limitations. First, sample size was low so that many differences in changes of costs over time as well as between data sources (self-report vs. administrative data) may not have been detected. Second, collection of cost data may have produced bias. Self-reported cost data is subject to under-reporting (28), and the complex derivation of costs by allocating unit costs to self-reported service use is prone to imprecision, also because unit costs might not always reliably reflect actual costs. Third, administrative records were only available for the insurees of one statutory health insurance (AOK Swabia), and costs incurred by insurees of other statutory or private health insurance companies might be different. For a complete assessment of the study participants' health insurance records, agreements would have had to be made with 20 other statutory or private health insurance companies which was not feasible. However, representativeness of the cost data from administrative records can be assumed to be reasonable, given that the AOK Swabia is responsible for the reimbursement of costs of the largest share of patients receiving psychiatric inpatient care at the clinic where the study took place. Fourth, explained variance was rather low in the models examining the pre-post differences of total and subtypes of treatment costs, suggesting there may be other explanatory variables not assessed in this study. Fifth, regarding the comparison between administrative and self-reported cost data, equivalence of the average cost per patient does not indicate complete congruence. Differences in the indication of any treatment and costs given any use may 
result in similar average costs per person. Finally, due to the lack of a counterfactual, i.e. data on the "natural" flow of costs without inpatient treatment, findings do not allow a causal interpretation in the sense of an "effect" of inpatient treatment on course of costs.

\section{Conclusion}

This study examined differences of health care costs before and after psychiatric inpatient treatment in people with mental illness. Total and subtypes of treatment costs increased after discharge from inpatient treatment. No cost differences over time between self-reported and administrative records were found suggesting that self-report data adequately measure the costs of health services in people with mental illness.

Taken together, findings suggest a pattern of limited engagement in community treatment prior to hospitalization and more extensive engagement afterwards. The increase in health service use after inpatient treatment can be seen as positive, while the pre-inpatient level of care is a potential problem, raising the question whether more or better outpatient care might have reduced the likelihood of requiring hospital care. Findings may serve as a basis for future studies aiming at furthering the understanding of what to expect regarding appropriate levels of post-hospital care, and what factors may help or inhibit post-discharge treatment engagement. Future studies should also scrutinize differences over time between self-reported and administrative records of service use in larger samples of people with mental illness and other health conditions.

\section{Acknowledgements}

This work was supported by the German Federal Ministry of Education and Research (grant number 01GL0504). The authors are grateful to Carina Knaup, Dorothea Schöfer, Paulo Kling Lourenço, and Constanze Lahmeyer (Department of Psychiatry II, Ulm University, Ulm, Germany) for the collection of study data; to Ferdinand Beylacher, UliGerd Prillinger, Oliver Dietrich, Susanne Fischer, Peter Sørre Thomas Koch, and Herbert Augustin (AOK Swabia, Germany) for the provision of the administrative records; and to Reinhold Kilian (Department of Psychiatry II, Ulm University, Ulm, Germany) for comments on an earlier manuscript version. We also thank patients and clinicians at Ulm University's Clinic for Psychiatry and Psychotherapy II in Günzburg for participating in this study.

\section{Ethical issues}

The study was approved by UIm University's ethics committee.

\section{Competing interests}

The authors declare that they have no competing interests.

\section{Authors' contributions}

BP initiated the idea. NZ and IB prepared and analyzed data. NZ, IB and BP wrote the manuscript. TB critically revised the manuscript for important intellectual content. All authors gave final approval of the version to be published.

\section{References}

1. Leslie DL, Rosenheck R. Shifting to outpatient care? Mental health care use and cost under private insurance. Am J Psychiatry 1999; 156: 1250-7.
2. Kilbourne AM, Greenwald DE, Bauer Mark S, Charns MP, Yano EM. Mental health provider perspectives regarding integrated medical care for patients with serious mental illness. Adm Policy Ment Health 2012; 39: 448-57. doi: 10.1007/s10488-011-0365-9

3. Chi FW, Parthasarathy S, Mertens JR, Weisner CM. Continuing care and long-term substance use outcomes in managed care: early evidence for a primary care-based model. Psychiatr Serv 2011; 62: 1194-200. doi: 10.1176/appi.ps.62.10.1194

4. Madras BK, Compton WM, Avula D, Stegbauer T, Stein JB, Clark HW. Screening, brief interventions, referral to treatment (SBIRT) for illicit drug and alcohol use at multiple healthcare sites: comparison at intake and 6 months later. Drug Alcohol Depend 2009; 99: 280-95. doi: 10.1016/j.drugalcdep.2008.08.003

5. Druss BG, von Esenwein SA, Compton MT, Rask KJ, Zhao L, Parker RM. A randomized trial of medical care management for community mental health settings: the Primary Care Access, Referral, and Evaluation (PCARE) study. Am J Psychiatry 2010; 167: 151-9. doi: 10.1176/appi.ajp.2009.09050691

6. Butler M, Kane RL, McAlpine D, Kathol RG, Fu SS, Hagedorn H, et al. Integration of mental health/substance abuse and primary care. Rockville (MD): Agency for Healthcare Research and Quality; 2008.

7. Zubkoff L, Young-Xu Y, Shiner B, Pomerantz A, Watts BV. Usefulness of symptom feedback to providers in an integrated primary care-mental health care clinic. Psychiatr Serv 2012; 63: 91-3. doi: 10.1176/appi.ps.201100323

8. Chiverton $\mathrm{P}$, Tortoretti D, LaForest $\mathrm{M}$, Walker $\mathrm{PH}$. Bridging the gap between psychiatric hospitalization and community care: cost and quality outcomes. J Am Psychiatr Nurses Assoc 1999; 5: 46-53. doi: 10.1016/S1078-3903(99)90019-8

9. Tulloch $A D$, Fearon $P$, David AS. Length of stay of general psychiatric inpatients in the United States: systematic review. Adm Policy Ment Health 2011; 38: 155-68. doi: 10.1007/s10488010-0310-3

10. Rentmeester CA. Challenges for policy makers and organizational leaders: addressing trends in mental health inequalities. Int J Health Policy Manag 2013; 1: 99-101. doi: 10.15171/ ijhpm.2013.16

11. Bertakis KD, Azari R. Patient-centered care is associated with decreased health care utilization. J Am Board Fam Med 2011; 24: 229-39. doi: 10.3122/jabfm.2011.03.100170

12. Parthasarathy S, Mertens J, Moore C, Weisner C. Utilization and cost impact of integrating substance abuse treatment and primary care. Med Care 2003; 41: 357-67.

13. Chisholm D, Sekar K, Kumar KK, Saeed K, James S, Mubbashar $\mathrm{M}$, et al. Integration of mental health care into primary care. Demonstration cost-outcome study in India and Pakistan. $\mathrm{Br} J$ Psychiatr 2000; 176: 581-8.

14. Mitton CR, Adair CE, McDougall GM, Marcoux G. Continuity of care and health care costs among persons with severe mental illness. Psychiatr Serv 2005; 56: 1070-6. doi: 10.1176/appi. ps.56.9.1070

15. Salize HJ, Rössler W, Becker T. Mental health care in Germany: current state and trends. Eur Arch Psychiatry Clin Neurosci 2007; 257: 92-103. doi: 10.1007/s00406-006-0696-9

16. Federal Statistical Office. 20 Jahre Krankenhausstatistik [20 years of hospital statistics]. 2012. [cited 2014 Aug 7]. Available from: https://www.destatis.de/DE/Publikationen/WirtschaftStatistik/ Gesundheitswesen/20JahreKrankenhausstatistik.pdf? blob=publicationFile

17. SpießI H, Binder H, Cording C, Klein HE, Hajak G. Psychiatric inpatient care under economic pressure. Dtsch Arztebl 2006; 103: 2549-52.

18. Federal Statistical Office. Krankheitskostenrechnung Deutschland [Calculation of costs of illness in Germany]. 2010. [cited 2014 Aug 7]. Available from: http://www.gbebund.de/oowa921-install/servlet/oowa/aw92/dboowasys921. xwdevkit/xwd_init?gbe.isgbetol/xs_start_neu/\&p_aid=3\&p aid $=26772121 \&$ nummer $=554 \& p \_s p r a c h e=D \& p \_$indsp $=-\& p$ aid $=44458760$

19. Olfson M, Sing M, Schlesinger HJ. Mental health/medical care 
cost offsets: opportunities for managed care. Health Aff 1999; 18: 79-90. doi: 10.1377/hlthaff.18.2.79

20. Kocakülah MC, Valadares KJ. Cost offset effect strategies for the provision of mental health care services. $J$ Health Care Finance 2003; 30: 31-40.

21. Mumford E, Schlesinger HJ, Glass GV, Patrick C, Cuerdon T. A new look at evidence about reduced cost of medical utilization following mental health treatment. Am J Psychiatry 1984; 141: 1145-58.

22. Chiles JA, Lambert MJ, Hatch AL. The impact of psychological interventions on medical cost offset: a meta-analytic review. Clin Psychol Sci Pract 1999; 6: 204-20. doi: 10.1093/clipsy.6.2.204

23. Katon W, Unutzer J, Fan MY, Williams JW Jr, Schoenbaum M, $\mathrm{Lin} \mathrm{EH}$, et al. Cost-effectiveness and net benefit of enhanced treatment of depression for older adults with diabetes and depression. Diabetes Care 2006; 29: 265-70. doi: 10.2337/ diacare.29.02.06.dc05-1572

24. Fifer SK, Buesching DP, Henke CJ, Potter LP, Mathias SD, Schonfeld $\mathrm{WH}$, et al. Functional status and somatization as predictors of medical offset in anxious and depressed patients. Value Health 2003; 6: 40-50. doi: 10.1046/j.15244733.2003.00148.x

25. Holder HD, Blose JO. Changes in health care costs and utilization associated with mental health treatment. Hosp Community Psychiatr 1987; 38: 1070-5.

26. Maynard C, Cox GB, Krupski A, Stark K. Utilization of services for mentally ill chemically abusing patients discharged from residential treatment. J Behav Health Serv Res 1999; 26: 219-28. doi: $10.1007 / B F 02287493$

27. Gater R, Goldberg D, Jackson G, Jennett N, Lowson K, Ratcliffe $\mathrm{J}$, et al. The care of patients with chronic schizophrenia: a comparison between two services. Psychol Med 1997; 27: 132536. doi: 10.1017/S0033291797005631

28. Zentner N, Baumgartner I, Becker T, Puschner B. [Health service costs in people with severe mental illness: patient report vs. administrative records]. Psychiatr Prax 2012; 39: 122-8. doi: 10.1055/s-0031-1298869

29. Puschner B, Schöfer D, Knaup C, Becker T. Outcome management in in-patient psychiatric care. Acta Psychiatr Scand 2009; 120: 308-19. doi: 10.1111/j.1600-0447.2009.01397.x

30. Roick C, Kilian R, Matschinger H, Bernert S, Mory C, Angermeyer MC. [German adaptation of the Client Sociodemographic and Service Receipt Inventory - an instrument for the cost of mental health care]. Psychiatr Prax 2001; 28: 84-90. doi: 10.1055/s2001-17790

31. Chisholm D, Knapp MR, Knudsen HC, Amaddeo F, Gaite L, van Wijngaarden B. Client Socio-Demographic and Service Receipt Inventory-European Version: development of an instrument for international research. EPSILON Study 5. Br J Psychiatr Suppl 2000; 177: S28. doi: 10.1192/bjp.176.6.581

32. World Health Organization (WHO). International Statistical Classification of Diseases and Related Health Problems, 10th Revision. 2005. [cited 2014 Aug 7]. Available from: http://apps. who.int/classifications/apps/icd/icd10online2005/fr-icd.htm

33. Lambert MJ, Hannöver W, NissImüller K, Richard M, Kordy H. [Questionnaire on the results of psychotherapy: reliability and validity of the German translation of the Outcome Questionnaire 45.2 (OQ-45.2)]. Z Klin Psychol 2002; 1: 40-7. doi: 10.1026//16163443.31.1.40

34. Puschner B, Cosh S, Becker T. Patient-rated outcome assessment with the German version of the Outcome Questionnaire 45 in people with severe mental illness. Eur J Psychol Assess 2014: in press.

35. Lambert MJ, Burlingame GM, Umphress VJ, Hansen NB, Vermeersch DA, Clouse $\mathrm{G}$, et al. The reliability and validity of the Outcome Questionnaire. Clin Psychol Psychother 1996; 3: 106-16.

36. Federal Statistical Office. Krankenhausstatistik - Kostennachweis [Hospital statistics - cost statement]. 2010. [cited 2014 Aug 7]. Available from: http://www.gbe-bund.de/oowa921-install/servlet/ oowa/aw92/WS0100/_XWD_PROC?_XWD_282/2/XWD_CUBE. DRILL/ XWD 308/D.000/3722

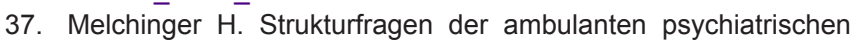
Versorgung [Questions of the structure of psychiatric outpatient care]. 2008. [cited 2014 Aug 7]. Available from: http://www.root. webdestination.de/kunden/01extern/bdn_redaktion_ssl_neu/ upload/kbv_gutachten_\%28endfassung_\%29.pdf

38. Krauth C, Hessel F, Hansmeier T, Wasem J, Seitz R, Schweikert B. [Empirical standard costs for health economic evaluation in Germany - a proposal by the working group methods in health economic evaluation]. Gesundheitswesen 2005; 67: 736-46. doi: 10.1055/s-2005-858698

39. Bavarian Association of Statutory Health Insurance Physicians (BASHIP). Honorarvertrag zwischen der KVB und der AOK Bayern 2006/2007 [Fee agreement between the Bavarian Association of Statutory Health Insurance Physicians and the AOK Bavaria]. 2006. [cited 2014 Aug 7]. Available from: http:// www.kvb.de/fileadmin/kvb/dokumente/Praxis/Rechtsquellen/ RQ-23Nt-Honorarvertrag-AOKUnterschriftsfassung-2006-2007inkIStrukturvertraege-fuer-OeO.pdf

40. National Association of Statutory Health Insurance Physicians. Einheitlicher Bewertungsmaßstab EBM, Stand 2008 - 4. Quartal [Uniform physicians' fee schedule]. 2008. [cited 2014 Aug 7]. Available from: http://www.kbv.de/media/EBM-2008-Archiv.zip

41. Rote Liste Service. Rote Liste: Arzneimittelverzeichnis für Deutschland [Red List: list of pharmaceuticals in Germany]. Frankfurt/Main: Rote Liste; 2007.

42. Kilian R, Matschinger H, Loeffler W, Roick C, Angermeyer MC. A comparison of methods to handle skew distributed cost variables in the analysis of the resource consumption in schizophrenia treatment. J Ment Health Policy Econ 2002; 5: 21-31.

43. Haberfellner EM, Grausgruber A, Grausgruber-Berner R, Ortmair $M$, Schony $W$. [Deinstitutionalization of long-stay psychiatric patients in upper Austria - utilization of healthcare resources and costs of outpatient care]. Psychiatr Prax 2006; 33: 74-80. doi: $10.1055 / \mathrm{s}-2004-828397$

44. Jerrell JM. Cost-effectiveness of risperidone, olanzapine, and conventional antipsychotic medications. Schizophr Bull 2002; 28: 589-605. doi: 10.1093/oxfordjournals.schbul.a006967

45. Stargardt T, Edel MA, Ebert A, Busse R, Juckel G, Gericke CA. Effectiveness and cost of atypical versus typical antipsychotic treatment in a nationwide cohort of patients with schizophrenia in Germany. J Clin Psychopharmacol 2012; 32: 602-7. doi: 10.1097/ JCP.0b013e318268ddc0

46. Newcomer JW. Second-generation (atypical) antipsychotics and metabolic effects: a comprehensive literature review. CNS Drugs 2005; 19: 1-93. doi: 10.2165/00023210-200519001-00001

47. Lang FH, Forbes JF, Murray GD, Johnstone EC. Service provision for people with schizophrenia. I. Clinical and economic perspective. Br J Psychiatr 1997; 171: 159-64. doi: 10.1192/ bjp.171.2.159

48. Merkesdal S, Bernitt K, Busche T, Bauer J, Mau W. [Comparison of Costs-of-illness in patients with low back pain 12 months prior and after orthopaedic inpatient and outpatient rehabilitation]. Rehabiliation 2004; 43: 83-9. doi: 10.1055/s-2003-814823

49. Raven MC, Doran KM, Kostrowski S, Gillespie CC, Elbel BD. An intervention to improve care and reduce costs for high-risk patients with frequent hospital admissions: a pilot study. BMC Health Serv Res 2011; 11: 270. doi: 10.1186/1472-6963-11-270 